\section{Student Perceptions of Instructor Supportiveness: What Characteristics Make a Difference?}

\author{
Elisabeth E. Schussler, ${ }^{+*}$ Maryrose Weatherton, ${ }^{\dagger}$ Miranda M. Chen Musgrove, ${ }^{*}$ \\ Jennifer R. Brigati, $\$$ and Benjamin J. England" \\ ${ }^{\dagger}$ Department of Ecology and Evolutionary Biology, University of Tennessee, Knoxville, TN 37996; \\ "Department of Ecology and Evolutionary Biology, University of Colorado Boulder, Boulder, CO \\ 80309; ' Department of Biology, Maryville College, Maryville, TN 37804; 'Department of Biology, \\ Saint Louis University, Saint Louis, MO 63103
}

\begin{abstract}
The use of active learning in the undergraduate biology classroom improves student learning and classroom equity, but its use can lead to student anxiety. Instructors can reduce student anxiety through practices that convey supportiveness and valuing of students. We collected students' ratings of their classroom anxiety and perceptions of their instructors' supportiveness, as well as open-response reasons for their ratings, in six large introductory biology classes. These data confirmed a negative relationship between student anxiety and student perceptions of their instructors' support. We used qualitative analysis to identify themes of instructor support and how these themes varied between instructors rated as providing higher or lower support by their students. Two instructors with higher-support ratings and two with lower-support ratings were selected for analyses. Inductive qualitative coding identified five themes of instructor support: relational (perception of caring/ approachability), instrumental (offering resources), pedagogical (quality of teaching), personality, and uncertain (not sure of support). Higher-support instructors had more positive relational themes and fewer negative pedagogical themes compared with lower-support instructors. These results can be used to enhance supportive classroom practices, which may be one mechanism to reduce student anxiety.
\end{abstract}

\section{INTRODUCTION}

Factors that influence the persistence of students in STEM (science, technology, engineering, and mathematics) degree programs have been the focus of many reform efforts, with particular interest in improving introductory STEM courses that can serve as initial barriers to degree progression for some students (President's Council of Advisors on Science and Technology, 2012). Some of these reform efforts, for example, have focused on providing greater structure to the curriculum (e.g., regular homework aligned with learning objectives; Eddy and Hogan, 2014) or more opportunities for students to engage with and practice their knowledge of course content and skills in class (e.g., active-learning strategies; Freeman et al., 2014). Studies testing the impacts of these strategies have documented improved student success, particularly for historically underserved students in science (i.e., first-generation students, Black, indigenous, and other students of color), suggesting they may be effective tools for increasing persistence (Eddy and Hogan, 2014; Theobald et al., 2020). However, these strategies change the nature of traditional class instruction and are not always embraced by students (Seidel and Tanner, 2013). Strategies such as active learning, for example, increase social interactions and public evaluation of responses (such as responding to verbal questions in front of classmates) that can be associated with negative student emotions, such as anxiety (Zeidner and Matthews, 2005; Broeckelman-Post et al., 2016; England et al., 2017, 2019; Cooper et al., 2018; Downing et al., 2020).
Tessa C. Andrews, Monitoring Editor Submitted Oct 19, 2020; Revised Mar 23, 2021; Accepted Mar 31, 2021

CBE Life Sci Educ June 1, 2021 20:ar29 DOI:10.1187/cbe.20-10-0238

*Address correspondence to: Elisabeth $\mathrm{E}$. Schussler (eschussl@utk.edu).

() 2021 E. E. Schussler et al. CBE-Life Sciences Education @ 2021 The American Society for Cell Biology. This article is distributed by The American Society for Cell Biology under license from the author(s). It is available to the public under an Attribution-Noncommercial-Share Alike 3.0 Unported Creative Commons License (http://creativecommons.org/licenses/ by-nc-sa/3.0)

"ASCB®" and "The American Society for Cell Biology $\circledR^{\prime \prime}$ are registered trademarks of The American Society for Cell Biology. 


\section{Student Anxiety}

Emotions in the classroom, such as anxiety, are powerful drivers of motivation, cognition, engagement, and performance (Pekrun, 1992, 2006; Kim and Pekrun, 2014; Mazer, 2017). Several researchers have found that students with higher anxiety are more likely to experience attrition from the major or degree (Witt et al., 2014; Barthelemey et al., 2015; Respondek et al., 2017). Yet, in comparison to other topics such as active learning, student emotions within introductory biology classrooms are relatively understudied.

Anxiety is the most common emotion undergraduate students report as part of their classroom experiences (Pekrun et al., 2002; Pekrun and Stephens, 2010). Anxiety is a prospective emotion that arises as a result of student appraisals of the value of a class-related task and their perceived control over task achievement; if students value the task but are not sure whether they have the ability to do well on the task, anxiety can arise (Pekrun, 2006). While student appraisals are hypothesized to be the proximal determinants of emotion, contextual characteristics (e.g., instructor practices, student prior experiences) also play a role (Pekrun, 2006; Pekrun et al., 2007).

We have previously examined the relationships between many aspects of student anxiety and students' performance and persistence in the biology major at our university (England et al., 2017, 2019). We examined overall anxiety in the class, perception of class difficulty, test anxiety, communication anxiety, and social anxiety; only overall anxiety had a significant negative relationship with students' intention to persist in the biology major (England et al., 2019). Although our original assumption was that anxiety resulting from active-learning practices would be related to student attrition, our results indicated that the anxiety related to attrition was broader than individual active-learning practices. We also noted that overall student anxiety varied among instructors in ways that did not seem aligned with the use of particular active-learning practices (England et al., 2017). Thus, we began investigating instructional practices (broadly encompassing instructor behaviors and other attributes) as potential factors impacting student anxiety in introductory biology classes.

\section{Instructor Practices and Student Emotions}

Some researchers have proposed that the interpersonal relationships between students and instructors are one of the main driving forces behind student emotion (Mainhard et al., 2018). Indeed, specific instructor emotions can be correlated with the same emotions in their students, likely through the observation of instructor behaviors that convey those emotions (Becker et al., 2014; Frenzel et al., 2018). This link between instructor emotion, instructor practices, and student emotion may be one explanation for why instructors teaching different sections of the same course at our university have different average student anxiety levels in their classes (England et al., 2017).

Many types of instructor verbal and nonverbal practices impact student emotions such as anxiety (Allen et al., 2006; Mazer et al., 2014; Witt et al., 2014). For example, instructor practices that generate a feeling of immediacy, which is a sense of psychological closeness between the instructor and student, can decrease student anxiety. Immediacy is generated through instructor use of verbal (e.g., using humor, using names) or nonverbal (e.g., smiling, eye contact) practices that positively impact student motivation, cognition, and emotion. Conversely, instructor verbal behaviors such as argumentativeness and verbal aggression can aggravate and heighten student anxiety in the classroom (Lin et al., 2017). These findings suggest that the words we use and ways we move in the classroom are closely monitored by students to inform their emotional reactions.

Another important way instructors alleviate or aggravate student anxiety is through their motivation style, which may include "autonomy-supportive practices" (Reeve, 2009). Autonomy-supportive practices are instructor behaviors that indicate interest and support for student goals, and these in turn motivate students to personally engage in the course (Reeve and Shin, 2020). Examples of autonomy-supportive practices include listening to students, providing explanations, using noncontrolling language, allowing self-paced learning, and acknowledging student feedback (Reeve, 2009). These practices are in contrast to controlling characteristics such as not justifying instructional choices to students, not listening to student opinions, and not adjusting instruction to student performance (Bartholomew et al., 2018). Instructors who are more autonomy supportive have students with higher levels of motivation and lower levels of anxiety (Black and Deci, 2000; Hall and Webb, 2014; Young-Jones et al., 2019). In introductory biology courses at our university, instructors who are perceived by their students as more autonomy supportive have classes with lower average student anxiety (B.J.E., J.R.B., and E.E.S., unpublished data).

\section{Conceptual Framework}

As outlined earlier, many instructor practices may be used by students as cues to judge the effectiveness of the instructor, the instructor's support for students, and subsequent student emotional response (Titsworth et al. 2013; Goldman and Goodboy, 2014; Mazer et al. 2014; Barthelemey et al., 2015). We represent these relationships in Figure 1 as informed by Pekrun's control-value theory of achievement emotion (Pekrun, 2006), which is an appraisal-based emotion theory. Pekrun's theory hypothesizes that the generation of student emotions is an outcome of appraisals students make about their perceived control over their achievement in the classroom and the value of those classroom achievements to them. These appraisals are personal, subjective, individual student perceptions about their agency or class achievement importance. Student value and control appraisals are made within the larger context of the learning environment, which includes distal factors such as student past experiences, institutional context, and classroom factors like peers and instructor. Once emotions are generated, student behaviors such as self-regulation, cognition, motivation, and so on play a role in determining the final impact on student achievement.

In the case of our study, we suggest that students are appraising instructor practices as part of the contextual characteristics of the learning environment. We hypothesize that students are appraising instructor practices to judge the level of support the instructor demonstrates toward student success, which then impacts student appraisals of the control they feel over their ability to achieve particular outcomes in the course. These control appraisals then determine the level of anxiety students feel toward the class. We call this framework the Instructor Practices-Student Anxiety framework (IPSA). The ramifications of 


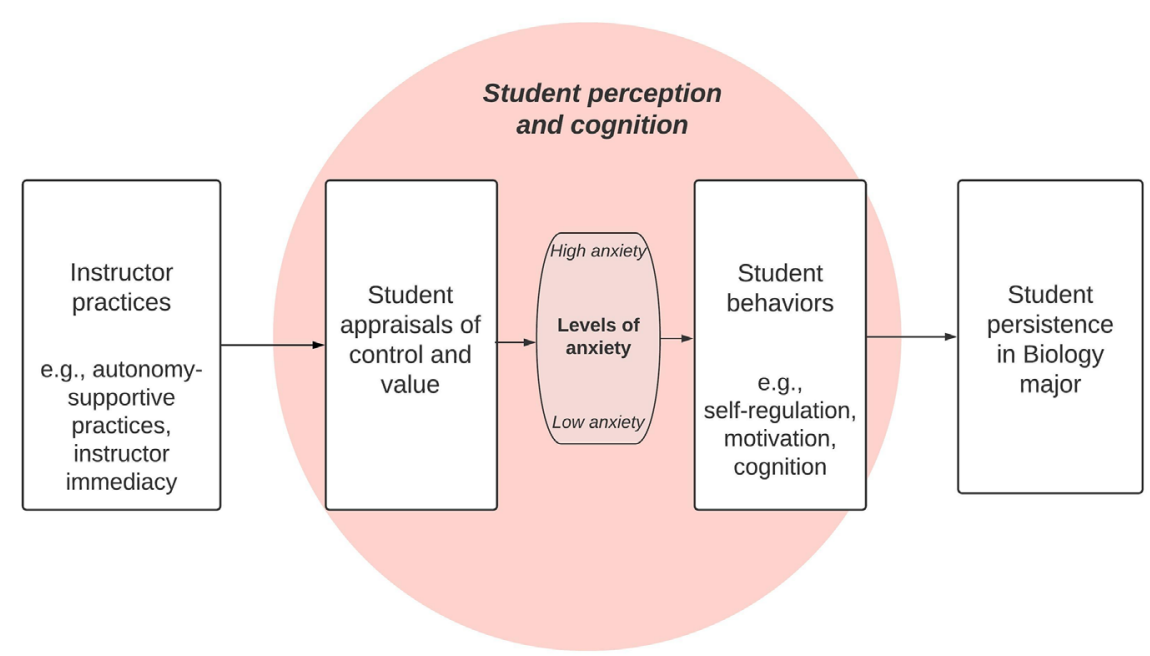

FIGURE 1. The Instructor Practices-Student Anxiety (IPSA) framework, which represents the conceptual relationships that underpin this study. Based on Pekrun's control-value theory of achievement emotions $(1992,2006)$ and our own research (England et al., 2017, 2019), anxiety arises from individual student appraisals of control and value related to course achievement. We suggest that students are also appraising instructor practices (including examples such as autonomy-supportive practices or instructor immediacy) to decide whether the instructor supports their success. If these appraisals suggest that instructor support is low, this likely decreases student appraisals of their control in their ability to do well in the course and increases student anxiety. This anxiety can then decrease persistence in the major unless positively impacted by student behaviors related to self-regulation, cognition, and/or motivation.

the IPSA are that certain instructors use practices that students perceive as less supportive, leading to lower appraisals of control, and therefore more anxiety; other instructors adopt practices that students perceive as more supportive of their learning, thus leading to higher appraisals of control and lower anxiety levels. Our data collection specifically explores these student perceptions of instructor support, and whether these instructor support perceptions are related to average class anxiety.

\section{Rationale and Research Questions}

The literature affirms the importance of what instructors say and do in the classroom as cues that students use to judge the classroom environment and appraise value and control to generate emotion. In essence, practices like immediacy and autonomy-supportive behaviors are "soft skills" instructors use to make students feel supported and valued, increasing their sense of belonging in the classroom (Freeman et al., 2010) and reducing their anxiety. Despite the potential importance of understanding how instructors convey support and which instructor practices students perceive as conveying support, these aspects are rarely studied in introductory biology classes. Thus, the purpose of this exploratory study was to investigate the construct of instructor support from the perspective of students in several introductory biology classes at our institution. Our research questions were:

1. How are student perceptions of instructor support related to student anxiety?

2. What instructor behaviors and attributes contribute to students' perceptions of higher versus lower supportiveness?
Delineating these instructor support practices can inform future studies about instructor awareness of their support behaviors or the specific types of instructor support that impact student anxiety levels.

\section{METHODS}

We conducted this study in Fall 2019 at a large research university in the Midsouth. To answer our research questions, we surveyed students in six large (approximately 220 students) introductory biology classes; three 3-credit organismal biology courses and three 3-credit cellular biology courses. These courses are two of the three introductory biology courses taken by biology majors at this institution, although students in many other disciplines also take these courses. Each course was taught by a different instructor, and all of the instructors had taught the courses before.

\section{Data Collection}

We collected data through an online survey that was sent to instructors, who distributed it to their students during week 4 of the class. The instructors were given email wording to send to students along with the survey link; the survey link took students to the Institutional Review Board-approved consent information and the survey items. Instructors could offer up to 5 points to their students for completing the survey, which was solely at the discretion of the instructor. The courses were 1000 points each, making this incentive a minor part of the grade. Students could take the survey to earn the points but decline to have their data included in the study. This study was approved by the Institutional Review Board before data collection (IRB-16-03181-XP).

The survey assessed students' perceived general (overall) anxiety level in the lecture class through four response items: "Biology lecture makes me nervous," "Biology lecture is stressful," "Biology lecture makes me anxious," and "Biology lecture is scary." Students provided their answers on a Likert scale from 1 to 7 , where 1 was strongly disagree and 7 was strongly agree. Thus a higher score meant higher anxiety. After these items, students answered an open-ended question about why they felt that way about biology class this semester. The Likert-scale items were modified by England et al. (2019) from a research anxiety survey by Papanastasiou and Zembylas (2008). England et al. (2019) replaced the word "research" with "biology lecture" for each question and used confirmatory factor analysis to test the validity of these items for measuring anxiety. Because this survey was used with a similar student population for this study, we did not revalidate the survey items.

Students were also asked to rate their instructor on a scale from 1 (not supportive) to 10 (very supportive) in response to the question: "How supportive is the instructor of your biology class?" We chose a scale of 1 to 10 for its discriminating power and student preference for this number of points (Preston and Colman, 2000). For each question, we asked a follow-up 
open-ended question: "Please explain why you rated your instructor's support the way you did." Given that we created the support question for this study, this open-ended question served as a response process validation wherein participants explain their responses to verify their understanding of the rating item (Arjoon et al., 2013).

We then asked students for basic demographic information (year in school, gender identity, racial identity, and ethnicity) as well as their majors and biology instructors' names.

\section{Data Analysis}

We used the four anxiety items, the one instructor support item, and the open-ended response explaining the support rating as the data for this study. Based on the valid and reliable data collected from England et al. (2019), we followed the same proto$\mathrm{col}$ and averaged the four anxiety items to get a general anxiety score for each student (out of 7 possible points). We then sorted the student data by instructor. Student ratings of anxiety and perceptions of instructor support were averaged for each instructor. To answer the first research question regarding the relationship between student anxiety and instructor support, we conducted a Pearson correlation test between these two variables. To compare the instructional behaviors and attributes of high- and low-support instructors, we chose the two instructors with the lowest average student ratings of support and the two instructors with the highest average student ratings of support to analyze.

We conducted qualitative analysis on the student explanations of their support ratings $(N=550)$ for these four instructors. We followed a basic qualitative analysis framework in which we inductively searched for codes within the responses (open coding), compiled similar codes (axial codes), and then sorted codes into categories, which we called themes (Merriam and Tisdell, 2016). To increase validity and reliability, we used a peer examination approach wherein all authors participated in the qualitative analysis to check the interpretation and assess reliability of the code assignments.

Three of the authors (E.E.S., M.W., M.M.C.M.) independently read the randomized student responses and conducted initial open coding. They and a biology education researcher external to the analysis team met to discuss and develop an initial codebook. The primary author (E.E.S.) then used the initial codebook to test the use of the codes and propose a grouping of the codes into four themes. Three of the themes could be positive or negative based on the wording the student used to describe the instructor support. If the wording was inconclusive, we used the support rating to assign the comment as positive or negative (e.g., above a 5/10 would be positive, while below 5/10 would be negative). If the rating and comment were neutral, we placed that response into a neutral code.

We then assigned a small subset of student responses to each author to independently code as a test of the codebook. The student responses were randomized before analysis so that they were not grouped by instructor, anxiety levels, or support ratings. We defined a coding unit as one student response, and researchers could assign as many codes to that unit as needed to reflect the response. After this initial coding test, the codebook was revised based on difficulties the team had in assigning codes. At this time, we added a fifth theme related to students expressing uncertainty about how supportive their instructor was because of how often this appeared in the data set. After verifying the new codebook, we assigned new subsets of the data to each coder for the final round of coding. The primary author (E.E.S) coded all student responses (primary coder), and the four coauthors each coded $25 \%$ of the student responses to provide a second set of codes (secondary coders).

After this coding round, the primary coder identified all agreements and disagreements in the two sets of codes. Interrater agreement was calculated by dividing the percent of codes that the coders agreed on by the total number of codes assigned. The primary coder and two of the secondary coders (M.W., M.M.C.M.) then reconciled all coding conflicts via discussion. The final codes and themes, along with examples of each code from student comments, are shown in Figure 2.

Once coded, the data set had positive and negative variants of three themes (relational, pedagogical, and personality), positive instrumental, and uncertain. We removed neutral relational and pedagogical codes from the data set, because there were only four total. We organized the support themes in two different ways to visualize their alignment with student ratings of instructor support. First, we calculated the percent of each of the themes that made up each of the student ratings of support (1 through 10). This indicated which themes were more prevalent at each rating. We then calculated the percent of themes for each of the four instructors who had previously been identified as lower support $(N=2)$ and higher support $(N=2)$. We calculated the percentages of themes for each instructor using the number of student respondents in each class so as not to bias the results based on differences in number of themes among instructors.

\section{RESULTS}

After removing incomplete and non-consenting student data, we had 897 participant responses to the survey. There were 1320 students in the six classes, so the overall response rate was $68.0 \%$. These students were mostly white, sophomore-level women (Table 1).

Student responses per class varied from 117 to 184 students, with response rates ranging from $54.9 \%$ to $80.7 \%$ of the class. Individual student anxiety scores ranged from 1 (low anxiety) to 6.75 (out of 7), with an average anxiety level of 3.17. Student-provided instructor support ratings ranged from 1 to 10 (high support), with an average of 7.32 across all participants. For each instructor, average class anxiety ranged from 2.39 to 4.33 (out of 7; Table 2). Average instructor support ranged from 5.60 to 8.30 for each class (out of 10; Table 2).

We found a small but significant negative correlation between student self-reported anxiety and ratings of instructor support $(r=-0.358, p<0.01)$. This supports the hypothesis that a higher student anxiety level tended to be associated with lower perceived levels of instructor support in these courses.

Based on the average support ratings for each instructor, we selected Mia, Lee, Jan, and Ken (instructor pseudonyms) for the qualitative analysis of student support responses, because they had the two highest and two lowest student support averages, respectively. Students of these four instructors represented 635 of the 897 students in the original data set. There was one man and one woman instructor who were rated as lower in support, Ken and Jan, and one man and one woman who were rated as higher in support, Lee and Mia. The two low-support 
Themes

Codes

Examples
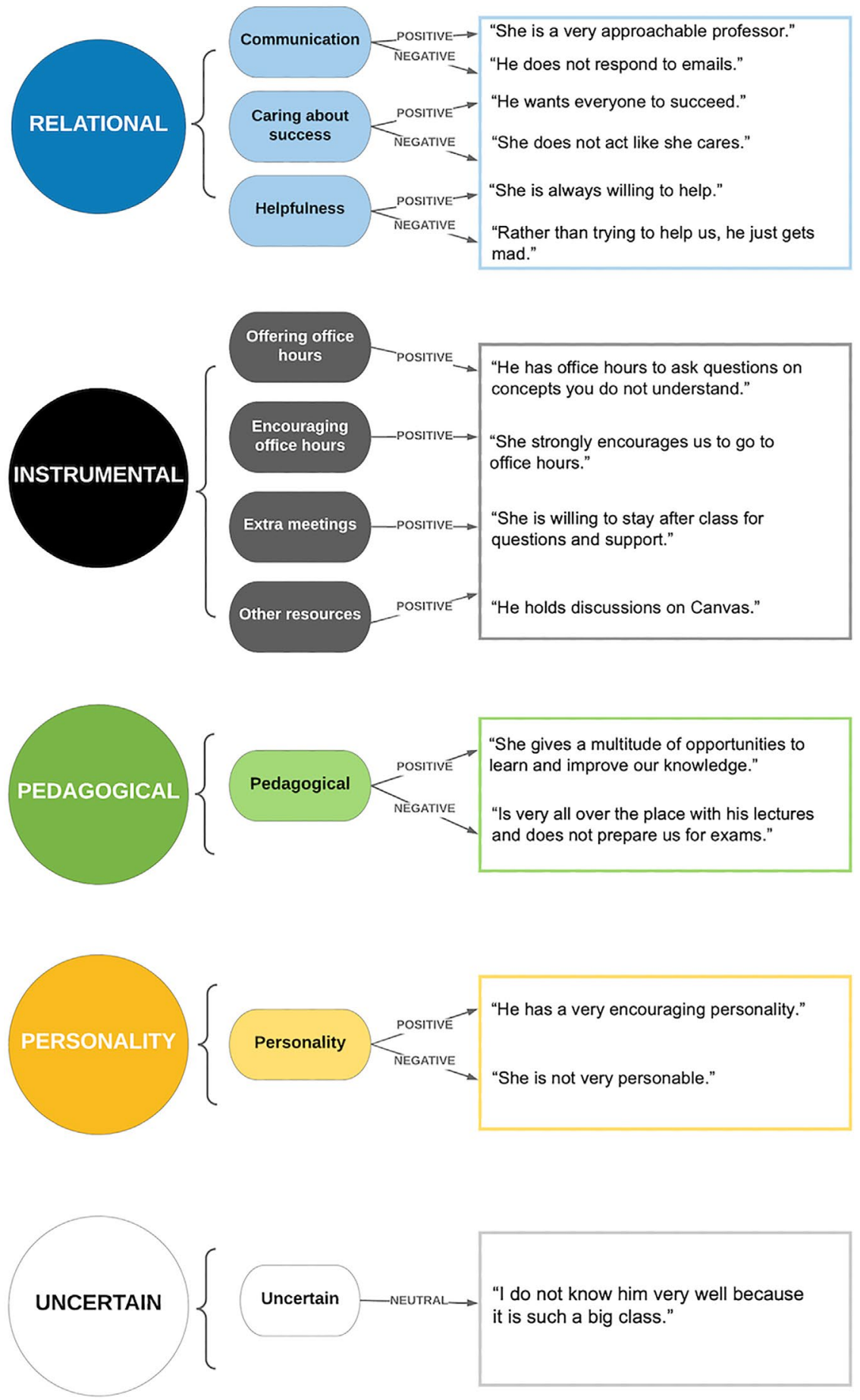

FIGURE 2. Codes and themes derived from student responses regarding supportiveness of their instructors. Some themes included a single code, while others included multiple codes. Student comments could be positive (saying something they perceived as being supportive), negative (saying something they perceived as not being supportive), or neutral (stating a fact or attribute that did not indicate positionality in terms of support). In the figure, the codes are in the middle, with the themes that these codes were grouped into on the left. Examples of quotes for each code, including exemplars of positive and negative comments, are shown on the right. and the two high-support instructors represented each course in the study (Table 2). Furthermore, Ken and Jan (lower support) had students with the highest average anxiety levels. Mia had students with the lowest average anxiety levels, while Lee had a midlevel of class average anxiety compared with the rest of the instructors.

\section{Five Themes of Instructor Support Were Identified from Student Responses}

Coding of student explanations for their support ratings $(N=550)$ resulted in five themes: relational, instrumental, pedagogical, personality, and uncertain (Figure 2). Relational, pedagogical, and personality themes could be positive $(+)$ or negative $(-)$; instrumental support was always positive; and uncertain was fully neutral. There were 850 codes assigned to the student support explanations. The interrater agreement between the primary and secondary coders was $76 \%$.

The relational theme $(33.1 \%$ of codes; $51.4 \%$ of student respondents) represented codes for which students described instructor support or nonsupport in a way that indicated an interaction with the instructor, how they thought the instructor conveyed caring or support to them, or the instructor's efforts on behalf of the student. These perceptions may have been based directly on their memory of things the instructor said, but it was clear that they were mostly based on a feeling they got about the way the instructor felt about them or how it felt to interact with that instructor (using words like "seems" or "feels"). One student indicated a relational code by saying, "He is helpful when I have questions, and when I was ot [sic] sick he stayed in contact with me and made me confident that missing for an illness was not the end of the world." Another student said, "He always says that he hopes everyone gets an A on the lecture quizzes which is really nice." These represented positive codes related to helpfulness and caring. Other students indicated more negative codes, such as “I don't feel like I could go to him for extra help because I'm afraid he'd judge me for being confused," which indicated a negative communication code. Another student said, "He seems to know everything and isn't very willing to help us understand. He doesn't want to answer dumb questions." This represented a negative helpfulness code. 
TABLE 1. Demographic information of the student sample $(N=897)^{a}$

\begin{tabular}{lcc}
\hline & $\begin{array}{c}\text { Self-reported raw } \\
\text { numbers }\end{array}$ & $\begin{array}{c}\text { Percentage of total } \\
\text { participants }\end{array}$ \\
\hline Gender & & \\
$\quad$ Man & 248 & 27.6 \\
$\quad$ Woman & 639 & 71.2 \\
Ethnicity & & \\
$\quad$ White & 674 & 75.1 \\
Non-white & 183 & 20.4 \\
Year & & \\
1 & 280 & 31.2 \\
2 & 445 & 49.6 \\
3 & 122 & 13.6 \\
$4+$ & 49 & 5.5 \\
\hline
\end{tabular}

aStudents self-reported this information and not all students responded to all questions, thus percentages do not add up to 100 . Ethnicity was sorted as white or non-white, with non-white indicating any student responding with anything other than white or Caucasian (including Black, Latinx, Asian, biracial, etc.)

The instrumental theme (10.7\% of codes; $16.6 \%$ of student respondents) encompassed codes for which the student described the instructor helping outside class time. The description had to clearly indicate that this was occurring outside class; if not, the default was to assign a pedagogical code (see next paragraph; e.g., "helps us to know what to study" would be assigned as pedagogical, not instrumental, because when that occurred was not made clear). Students never indicated a negative instrumental support code; instead, these codes always indicated the instructor doing something extra, so we coded these as positive. For example, one student said, "She stays after class to discuss questions," indicating the code of offering extra meetings. Another student indicated, "He has discussions through Canvas that everyone can communicate on. He also has office hours to ask questions on concepts you do not understand." This shows the codes of extra resources and offering office hours.

The pedagogical theme (34.0\% of codes; $52.6 \%$ of student respondents) arose with student responses related to some aspect of teaching and learning that they ascribed to feelings of support, or lack thereof, by the instructor. It may have been related to teaching practices, pace of delivery, ability to answer questions, or other in-class perceptions, but it always related to how they felt learning occurred in the classroom. Overall, quotes in this theme described whether instructors conveyed or not through their teaching that they cared specifically about their students' learning. For example, one student perceived a positive pedagogical aspect by saying, "He is passionate about what he teaches and it is also his field of work so he shares excitement and knowledge." Another said, "I feel as if my instructor does all that he can to help us learn the material and provide times for questions if it is needed." These represented positive codes related to this theme. Negative responses included: "I do not think she really explains the material very well. Instead of explaining something step by step, she just sort of throws you to the wolves." or "My bio lecture instructor just gets up there and reads his slides and expects us to know the information." In both cases, the students perceived that the instructor was not using class time to help them learn. Interestingly, students rarely commented on active-learning practices or pedagogical choices related to it, but instead commented about more general teaching practices, whether positive or negative (e.g., taking time to answer questions or just "reading slides").

The personality theme ( $6.6 \%$ of codes; $10.2 \%$ of student respondents) arose when students described the way they perceived the instructor as a person as an indicator of their supportiveness. It was distinguished from the relational category, because relational codes were the way the instructor treated the students or the way the students thought the instructor felt about them, whereas personality was the way the students viewed the instructor as a person. As with the relational and pedagogical themes, this had positive and negative aspects. For example, one student said about a professor, "He has a very encouraging personality." Another said, "She is a very welcoming and optimistic person, and that's good when it comes to being a teacher." On the negative side, another student said, "I haven't talked a lot to my professor. He's a little intimidating," which indicates the potential for a lack of communication. Another student said that an instructor was "not very personable." Although it was sometimes hard to understand why students would link personality traits with support ratings, it was clear that the ability to communicate or have a connection with their instructors was important to them, suggesting that personality traits and relational traits may be linked in students' minds.

The last theme was uncertain $(15.5 \%$ of codes; $24.0 \%$ of student respondents), which was when a student indicated being unable to tell how supportive an instructor was. This was often because the student felt the course was too large and/or was not able to connect with the instructor. This lack of connection seemed to result in a feeling of detachment or indifference

TABLE 2. The average student anxiety ratings and instructor support ratings ( \pm SD) for each of the six instructors in this study

\begin{tabular}{llccr}
\hline Instructor $^{\mathrm{a}}$ & Gender, course & $\begin{array}{c}\text { Average student anxiety } \\
\text { (range 1-7) }\end{array}$ & $\begin{array}{c}\text { Average support rating } \\
\text { (range 1-10) }\end{array}$ & $\begin{array}{c}\text { Number of student } \\
\text { responses (response rate) }\end{array}$ \\
\hline Mia & W, cellular & $2.39 \pm 1.31$ & $8.30 \pm 1.67$ & $184(80.7 \%)$ \\
Lee & M, organismal & $3.14 \pm 1.50$ & $8.24 \pm 1.71$ & $144(61.5 \%)$ \\
Ian & M, organismal & $3.13 \pm 1.60$ & $7.94 \pm 2.03$ & $145(62.8 \%)$ \\
Pam & W, cellular & $2.92 \pm 1.45$ & $7.07 \pm 2.16$ & $117(54.9 \%)$ \\
Jan & W, cellular & $3.32 \pm 1.59$ & $6.48 \pm 1.99$ & $171(79.2 \%)$ \\
Ken & M, organismal & $4.33 \pm 1.74$ & $5.60 \pm 2.28$ & $136(68.7 \%)$ \\
\hline
\end{tabular}

anstructor names are pseudonyms.

${ }^{\mathrm{b}} \mathrm{M}$, man; W, woman. Cellular and organismal indicate which of the courses they taught. 
about the instructor. This was not coded as positive or negative, and often accompanied a support rating in the middle of the 1-10 scale. For example, one student indicated, "He does not get the opportunity to be very supportive for everybody because the class is simply to [sic] big to give that much attention to all of the students." Another student indicated, "I am honestly not sure how supportive he is. I haven't personally spoken with him about anything. I am too nervous to." In general, students either mentioned the size of the class as a factor in their uncertainty or not having met the instructor so they could not judge how supportive that instructor was.

Most student responses were sorted into the positive relational theme (29.4\% of codes), followed by positive pedagogical (25.4\%), and uncertain (15.5\%). Overall, relational and pedagogical themes dominated the student responses. The raw numbers and percentages of themes for the data set are shown in Table 3.

\section{Relational and Pedagogical Themes Were Most Likely to Be Aligned with Student Support}

When the eight themes (including positive and negative) were aligned with the student ratings of instructor support (Figure 3), a clear pattern of themes changing with increasing support ratings emerged. More than half the codes at low-support ratings (less than 5/10) were categorized into the negative pedagogical or negative relational themes. These two themes largely disappeared as ratings climbed above support ratings of six out of 10 . Unsurprisingly, the uncertain theme prevailed at midlevel support ratings. As student support ratings rose above six out of 10, positive relational, instrumental, positive pedagogical, and positive personality themes appeared to increase. Of these, codes related to the positive relational and positive pedagogical themes dominated.

We compared the support themes for lower- (Ken and Jan) and higher-support (Lee and Mia) instructors to identify differ-

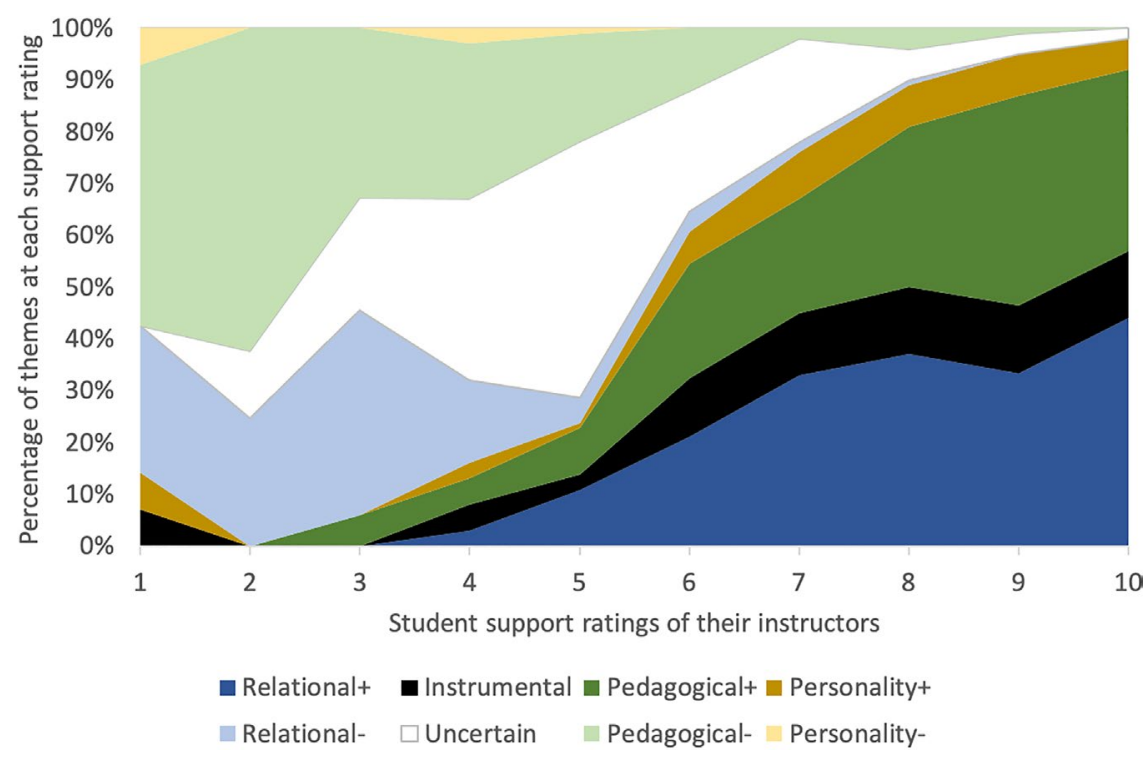

FIGURE 3. Changes in the percent of support themes at each student support rating, from 1 (low instructor support) to 10 (high instructor support). Darker colors are positive themes, lighter colors are negative. Theme key is shown at the bottom. ences in support characteristics (Figure 4). Lee and Mia had a higher frequency of positive relational themes than Ken and Jan. Negative relational themes did not uniformly differ among the two sets of instructors. Positive pedagogical themes trended higher for Lee and Mia, but the main difference appeared to be an almost complete lack of negative pedagogical themes for high-support instructors. There appeared to be slightly higher positive personality comments for high-support instructors, but the percentages for these themes were very low for all instructors. There were no distinct trends in instrumental and uncertain themes between high- and low-support instructors.

\section{DISCUSSION}

This study was in response to previous work on student anxiety at our university (England et al., 2017; B.J.E, J.R.B, and E.E.S., unpublished data) that suggested links between instructor practices and average class anxiety. We confirmed a statistically significant negative correlational relationship between student perceptions of instructor support and average anxiety in this study. As student perceptions of instructor support increased, student self-reports of anxiety levels decreased. In investigating what instructor practices these students associated with support, we found five themes. Instructor behaviors and attributes associated with the relational and pedagogical support themes were the two most frequently mentioned characteristics related to students' perceptions of support. In particular, negative relational and pedagogical themes were frequently associated with low-support ratings, while positive relational and pedagogical themes were frequently associated with higher-support ratings. In fact, when compared with low-support instructors, high-support instructors not only had more positive codes, they had far fewer negative ones. Thus, we suggest that students feel the most supported by instructors who have open communication lines with students, demonstrate caring and helpfulness toward their students, and teach with characteristics that show they are attending to student learning (such as answering student questions, watching their pace, explaining the material well, etc.). Given that students with instructors using these practices felt less anxiety about their biology class, these practices may help to support the persistence of more students in the biology major.

In the Introduction, we presented the IPSA framework based on Pekrun's control-value theory of achievement emotion (Pekrun, 2006) and our own work on student anxiety in our biology courses (England et al., 2017, 2019). IPSA posits that students appraise instructor support via the practices instructors use, which then inform student appraisals of control and the generation of student anxiety levels. In this study, we were able to empirically link our hypothesized relationships between student perceptions of instructor support and student anxiety levels. Specifically, we can now narrow down relational and pedagogical features of instructor practices as the contextual features that 


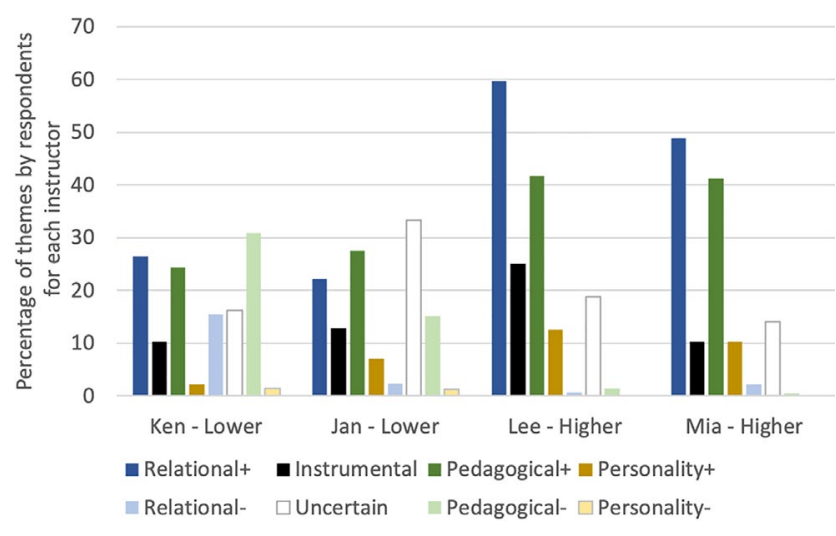

FIGURE 4. Percent of support themes (based on the number of student respondents for each instructor) for the two instructors with relatively lower student support ratings (Ken and Jan; $N=136$ and $N=171$, respectively) and the two instructors with relatively higher student support ratings (Lee and Mia; $N=144$ and $N=184$, respectively). Darker colors are positive themes, lighter colors are negative. Theme key is shown at the bottom.

may matter most to student appraisals of support. This study, however, did not collect data on student appraisals of control, which remains an untested link between perceptions of instructor support and student anxiety. We also assume that appraisals of value are less impacted by instructor support practices, but this needs to be tested. Also unknown are the exact instructor behaviors that result in students rating an instructor as high in relational or pedagogical support. These specific behaviors need to be empirically investigated in classroom contexts with instructor observations and student surveys to guide recommendations to faculty about how to convey support to students.

\section{Instructor Support Is Relative and Can Vary by Theme}

Individual instructors were not rated as high support or low support for all themes; the specific combination of high and low support for each theme were unique to each instructor. Jan, for example, had relatively low frequencies of negative relational behaviors, but had a much higher frequency of negative pedagogical behaviors, indicating that her students found her relational characteristics supportive, but her pedagogical character- istics not as supportive. Even the two lowest support-rated instructors had $20 \%$ of their students give them positive relational and positive pedagogical comments. The distinguishing feature between lower- and higher-rated instructors in this case was relatively higher percentages of negative themes for low-support instructors, indicating that more (but not all) students in their classes perceived their practices as low in support. This suggests that assessments of instructor support could be based on the relative proportion of positive and negative themes as opposed to focusing on positive or negative themes alone. However, because negative behaviors are more likely to be related to the generation of student anxiety, we do suggest that instructors focus on feedback about negative practices when making adjustments to instruction.

\section{Each Support Theme Has Implications for Instructor Practice}

Student descriptions of instructors' relational characteristics were one of the main features that distinguished higher- and lower-support instructors. Relational themes indicated an ease of communication with students, a perception of caring toward students, and helpfulness. All of these have distinct links with autonomy-supportive practices (Reeve, 2009), instructor immediacy (Allen et al., 2006), and instructor noncontent talk (Seidel et al., 2015; Harrison et al., 2019). Instructor noncontent talk consists of the words instructors say in the classroom that are not related to the course content. These verbal expressions can be used to build instructor-student relationships, establish classroom culture, explain pedagogical choices, and share personal experiences (Seidel et al., 2015). However, noncontent instructor talk can also be counterproductive if it generates distrust and feelings of unease in students (Harrison et al., 2019). While our data do not reveal the extent to which student perceptions of support were driven by things the instructor said versus things the instructor did, we know that both instructor actions and dialogue have the ability to alleviate or aggravate student anxiety, and thus impact student persistence. There is a large body of literature that highlights practices instructors can make use of to increase students' feelings of instructor caring and helpfulness. For example, sharing anecdotes about their own struggles in learning biology (Goldman and Goodboy, 2014), having class policies that indicate ways students can make up missed work (Young-Jones et al., 2019), or using nonverbal behaviors like eye contact and smiling (Allen et al., 2006). These, along with

TABLE 3. Number of codes assigned for each theme and percentages of each out of the total number of $\operatorname{codes}(N=850$ total codes) and out of the total number of open responses explaining their support ratings $(N=550)$

\begin{tabular}{lccc}
\hline Theme and directionality & $\begin{array}{c}\text { Number of codes for } \\
\text { each theme }\end{array}$ & $\begin{array}{c}\text { Percent out of total codes } \\
(N=\mathbf{8 5 0})\end{array}$ & $\begin{array}{c}\text { Percent out of respondents } \\
(N=550)\end{array}$ \\
\hline Relational (A+) & 250 & 29.4 & 45.5 \\
Relational (A) & 2 & 0.2 & 0.4 \\
Relational (A-) & 30 & 3.5 & 5.5 \\
Instrumental (B+) & 91 & 10.7 & 16.6 \\
Pedagogical (C+) & 216 & 25.4 & 39.3 \\
Pedagogical (C) & 2 & 0.2 & 0.4 \\
Pedagogical (C-) & 71 & 8.4 & 12.9 \\
Personality (D+) & 52 & 6.1 & 9.5 \\
Personality (D-) & 4 & 0.5 & 0.7 \\
Ambiguous (E) & 132 & 15.5 & 24.0 \\
\hline
\end{tabular}


other practices derived from the literature related to autonomy-supportive practices, may be ways to increase the persistence of students in the biology major, especially students historically underserved in science (Bauer et al., 2020).

Students in our study also seemed to connect positive pedagogical characteristics of their instructors with caring for learning as important support elements. In particular, the lack of negative pedagogical themes for higher support-rated instructors was striking. Negative pedagogical themes could include items such as the pace of the class being too fast, lack of enthusiasm from the instructor, perceived disorganization on the part of the instructor, or not listening to student feedback, to name a few. Instructors higher in these behaviors and attributes had students with higher anxiety. Many of the positive pedagogical elements our students identified are echoed by a recent study by Mimirinis (2020) on what characteristics students think make someone an excellent teacher, including enthusiasm, diagnosing student learning needs, breaking down the material, and maintaining a good pace. Students were definitive in the many ways that instructors were effective or ineffective in terms of their instruction, indicating close attention to this aspect of classroom culture. While relational codes often indicated that students were less certain about the source of their judgments (e.g., using words like "seem" or "think" to preface their comments), pedagogical codes often indicated exactly what an instructor was doing that the students did or did not like, suggesting the power of these practices to drive student perception. It should also be noted that even instructors who were rated lower in support had both negative and positive pedagogical comments about their instructional practices, once again suggesting that the class was not uniform in its perception of pedagogical support practices. An unknown, however, is the extent to which student judgments of effective or ineffective instruction were accurate reflections of classroom practice or were perhaps conflated with relational or personality factors. It is possible, for example, that instructors were doing an objectively effective job instructing, but did not effectively communicate a rationale for some of the pedagogical choices they were making (Brigati et al., 2019). We suggest that instructors have colleagues conduct peer observations of their classes and specifically attend to their pace, explanations, and how often they stop to clarify or ask for questions as indicators of support for student learning.

Instrumental codes were always positive, because they were things instructors were providing to the students in addition to their instruction. Examples of instrumental codes included offering and promoting office hours, offering review sessions, and other "bonuses" outside the scope of the classroom, such as discussion boards or optional extra class sessions. Interestingly, this theme did not appear to be the source of differences in student ratings of high- or low-support instructors, suggesting that all instructors were offering at least some of these opportunities. It is possible that these practices were seen by students as the instructor going above what was needed and were therefore viewed as supportive regardless of what was offered. One instructor (Lee) did have a relatively higher frequency of instrumental codes. His students were more likely to mention the offering of additional discussion boards and the encouragement to attend office hours, which may indicate that students do notice differences when instructors make extra efforts. Because this category was universally positive, instructors can easily convey support for student learning by mentioning extra resources and calling attention to their office hours.

The personality theme did not appear to be as useful for distinguishing or indicating instructor support; overall, it was the theme with the lowest prevalence in the data set. The personality traits mentioned-nice, kind, scary-may have been largely subsumed into the relational category, as most of these characteristics may play into perceptions by the students as to how the instructors treat them or behave toward them. Practices that foster immediacy (Allen et al., 2006), for example, may be interpreted by students in a relational sense rather than as a function of an instructor's personality, or vice versa. The lower prevalence of this theme in the data set may have indicated that students were reluctant to use personal characteristics of instructors as a factor to judge relationships with students or teaching effectiveness, perhaps sensing this was an unfair way to judge supportiveness.

The uncertain theme indicated that a certain proportion of students had difficulty appraising instructor support either because the student had not met the instructor personally yet, or because the class was too large to get to know the instructor. Comments related to this theme were seen most often in the mid-range of instructor support (scores of 4 to 6), suggesting a correlation between students providing an uncertain statement and reporting a "lukewarm" level of support. The survey was given in week 4, so students may truly not have formed opinions about their instructors yet; however, many other students in the same classes were able to make thorough relational or personality judgments within the same time period. This suggests that this theme may be driven by a subset of students in each class. One hypothesis is that some students are more sensitive to words or behaviors that their instructors may be conveying about their support, while other students are less sensitive to these characteristics; this aligns with a suggestion that some students are "cue seekers," while others are not (Miller and Parlett, 1974). In their analysis of what makes large lecture classes feel small, Cash et al. (2017) noted that instructor behaviors such as moving around the room and using smallgroup work could make a large class feel small to students. Thus, there are ways that instructors can decrease student perceptions of distance and develop the types of relationships that make students feel supported, even in large classes. For instructors who have high numbers of students who are uncertain about their level of support, it may be prudent to move around the class more, engage in small talk, and try to more intentionally connect with students.

\section{Limitations}

These study results were based on six large introductory biology classes at one institution and are exploratory in nature. The student responses were also mostly from white, sophomore-level, women, who do not represent a diversity of perspectives. These results may not be generalizable to different institutions, student populations, upper-level courses, or smaller-sized classes. For example, the uncertain theme would be expected to decline substantially in smaller classes in which students have more opportunity to speak with the instructor. It is also important to remember that these survey data were collected at week 4 of the class; this timing may have particularly 
impacted the pedagogical and uncertain themes, as students had not yet fully formed their judgments of the instructors or may not have had an assessment that would allow them to accurately judge the extent to which the pedagogical practices were preparing them for success on an exam or quiz.

Certainly, we would be remiss not to address the potential for gender differences in relation to instructor support. In this study, we had one man and one woman instructor in both lowand high-support categories, suggesting that student perceptions of support were not overall influenced by gender. Even when looking at the themes for each of the four instructors, there was no particular trend for any of the themes by gender. However, we cannot discount the potential that gender was a factor and support ratings and characteristics would have been different if the instructor was not of a particular gender; certainly, expectations for each gender can be different (El-Alayli et al., 2018; Clayson, 2019). Women instructors are often perceived less favorably in terms of knowledge but are expected to convey more positive relational characteristics.

We also note that the classes had students with relatively low average anxiety and relatively high perceptions of instructor support overall, so we were comparing relatively lower- and higher-support instructors versus extreme examples of low- and high-support instructors. The ratings of instructor support were based on a single author-created question. Using a validated multiple-item instrument to measure support may have provided more separation and nuance among student ratings. Finally, this study was not designed to explore differences in a statistical manner, which would need to be done to make more definitive statements about differences among instructors with different support ratings.

\section{Implications}

Student anxiety is not the same among students or classes, and neither was student-perceived instructor support. Students, and their responses to instructional practices, are not a monolith. Given this diversity in student anxiety and student perceptions of support, there is still much work to be done regarding how changes in instructional practice will impact student perceptions of support. In particular, the student results regarding the uncertain theme indicate that some students in a class will receive instructional messages differently than others, and we have little understanding of the factors that drive these differences in perceptions. Overall, further examination of the diversity of student perceptions of instructor behaviors and attributes is merited, especially for the two categories of instructor practices: noncontent instructor talk and pedagogical content delivery.

As work on noncontent instructor talk has found, the words instructors use in the classroom matter (Seidel et al., 2015; Harrison et al., 2019). And yet, many instructors spend hours preparing the content they will present with little thought about the words they say that are not related to the content. Researchers are just beginning to study the extent to which these unplanned words may drive student emotions such as anxiety and alter student motivation and cognition in the classroom and how intentional use of positive messages may help learning (Young-Jones et al., 2014; Bauer et al., 2020). Intentionality in our practices should certainly extend to both how we talk about content and how we support our students, as a way to generate a more equitable sense of belonging in our classrooms for all students (Freeman et al., 2010) and support positive student emotion (Becker et al., 2014). To this end, peer observations of instructor practice could include reflection on the noncontent aspects of the classroom as well as those related to the content.

We also suggest that instructors attend to best practices in their content delivery such as checking in with students on their understanding, watching pace, providing clear explanations, being open to answering student questions, and remembering that our excitement about the material is contagious. In an era when the use of active-learning practices has been the focus, it is important to remember that its use is not a panacea (Andrews et al., 2011). Good pedagogical practices linked with the conveyance of caring about students are equally important partners to active learning (Theobald et al., 2020). Indeed, it has been shown that student perceptions of their learning environments are stronger drivers of course outcomes than prior student experience (Lizzio et al., 2002) and that instructor characteristics of competence, trustworthiness, and caring are related to decreases in student anxiety (Witt et al., 2014). Thus, instructors need to curate classroom learning environments as much as they curate course content. Instructors should also remember that instructional decisions are often not clear to students and that there is great benefit to opening the black box of teaching to our students. Offering justification for pedagogical decisions may be one tool to mitigate negative perceptions of pedagogical choices (Reeve, 2009; Brigati et al., 2019).

\section{CONCLUSIONS}

We found that instructor practices linked with student perception of relational characteristics and pedagogical characteristics appeared to be most related to student perceptions of instructor support. This suggests that instructors should attend to the way they interact with students and how they are conveying support via their instruction. Given the established relationship we found between student levels of anxiety and their perceptions of instructor support, we suggest that relational and pedagogical characteristics could be used to mitigate student anxiety in our introductory courses. Future research could investigate whether alterations in instructor practices related to support can shift student anxiety, and more importantly, who these shifts benefit in terms of likely persistence in the biology major.

\section{ACKNOWLEDGMENTS}

The authors thank the instructors and students who participated in this study and Caroline Wienhold for feedback. Two anonymous reviewers and the monitoring editor provided valuable advice to improve this work.

\section{REFERENCES}

Allen, M., Witt, P. L., \& Wheeless, L. R. (2006). The role of teacher immediacy as a motivational factor in student learning: Using meta-analysis to test a causal model. Communication Education, 55(1), 21-31. https://doi .org/10.1080/03634520500343368

Andrews, T. M., Leonard, M. J., Colgrove, C. A., \& Kalinowski, S. T. (2011). Active learning not associated with student learning in a random sample of college biology courses. CBE-Life Sciences Education, 10, 394405. https://doi.org/10.1187/cbe.11-07-0061

Arjoon, J. A., Xu, X., \& Lewis, J. E. (2013). Understanding the state of the art for measurement in chemistry education research: Examining the psychometric evidence. Journal of Chemical Education, 90(5), 536-545. doi: 10.1021/ed3002013 
Barthelemey, R. S., Hedberg, G., Greenberg, A., \& McKay, T. (2015). The climate experiences of students in introductory biology. Journal of Microbiology \& Biology Education, 16(2), 138-147. https://doi.org/10.1128/ jmbe.v16i2.921

Bartholomew, K. J., Ntoumanis, N., Mouratidis, A., Katartzi, E., Thogersen-Ntoumani, C., \& Vlachopoulos, S. (2018, February). Beware of your teaching style: A school-year long investigation of controlling teaching and student motivational experiences. Learning and Instruction, 53, $50-$ 63. https://doi.org/10.1016/j.learninstruc.2017.07.006

Bauer, A. C., Coffield, V. M., Crater, D., Lyda, T., Segarra, V. A., Suh, K., .. Vigueria, P. A. (2020). Fostering equitable outcomes in introductory biology courses through use of a dual domain pedagogy. CBE-Life Sciences Education, 19(1), ar4. https://doi.org/10.1187/cbe.19-07-0134

Becker, E. S., Goetz, T., Morger, V., \& Ranellucci, J. (2014, October). The importance of teachers' emotions and instructional behavior for their students' emotions-An experience sampling analysis. Teaching and Teacher Education, 43, 15-26. https://doi.org/10.1016/j.tate.2014 .05 .002

Black, A. E., \& Deci, E. L. (2000). The effects of instructors' autonomy support and students' autonomous motivation on learning organic chemistry: A self-determination theory perspective. Science Education, 84(6), 740756. https://doi.org/10.1002/1098-237X(200011)84:6 $1740:: A I D-S C E 4 \geq 3.0$ .CO;2-3

Brigati, J. R., England, B. J., \& Schussler, E. E. (2019). It's not just for points: Teacher justifications and student perceptions about active learning. Journal of College Science Teaching, 48(3), 45-55. https://doi.org/ 10.2505/4/jcst19_048_03_45

Broeckelman-Post, M., Johnson, A., \& Schwebach, J. R. (2016). Calling on students using notecards: Engagement and countering communication anxiety in large lecture. Journal of College Science Teaching, 45(5), $27-$ 32. https://doi.org/10.2505/4/jcst16_045_05_27

Cash, C. B., Letargo, J., Graether, S. P., \& Jacobs, S. R. (2017). An analysis of the perceptions and resources of large university classes. CBE-Life Sciences Education, 16(2), ar33. doi: 10.1187/cbe.16-01-0004

Clayson, D. E. (2019). Student perception of instructors: The effect of age gender, and political leaning. Assessment and Evaluation in Higher Education, 45(4), 607-616. https://doi.org/10.1080/02602938.2019 .1679715

Cooper, K. M., Downing, V. R., \& Brownell, S. E. (2018). The influence of active learning practices on student anxiety in large-enrollment college science classrooms. International Journal of STEM Education, 5(23). https:// doi.org/10.1186/s40594-018-0123-6

Downing, V. R., Cooper, K. M., Cala, J. M., Gin, L. E., \& Brownell, S. E. (2020). Fear of negative evaluation and student anxiety in community college active-learning science courses. CBE-Life Sciences Education, 19(2) ar20. https://doi.org/10.1187/cbe.19-09-0186

Eddy, S. L., \& Hogan, K. (2014). Getting under the hood: How and for whom does increasing course structure work? CBE-Life Sciences Education, 13(3), 453-468. https://doi.org/10.1187/cbe.14-03-0050

El-Alayli, A., Hansen-Brown, A. A., \& Ceynar, M. (2018). Dancing backwards in high heels: Female professors experience more work demands and special favor requests, particularly from academically entitled students. Sex Roles, 79, 136-150. https://doi.org/10.1007/s11199-017-0872-6

England, B. J., Brigati, J. R., \& Schussler, E. E. (2017). Student anxiety in introductory biology classrooms: Perceptions about active learning and persistence in the major. PLoS One, 12(8), e0182506. https://doi.org/10.1371/ journal.pone.0182506

England, B. J., Brigati, J. R., Schussler, E. E., \& Chen, M. M. (2019). Student anxiety and perception of difficulty impact performance and persistence in introductory biology courses. CBE-Life Sciences Education, 18(2), ar21. https://doi.org/10.1187/cbe.17-12-0284

Freeman, S., Eddy, S. L., McDonough, M., Smith, M. K., Wenderoth, M. P., Okoroafor, N., \& Jordt, H. (2014). Active learning increases student performance in science, engineering, and mathematics. Proceedings of the National Academy of Sciences USA, 111(23), 8410-8415. https://doi .org/10.1073/pnas.1319030111

Freeman, T. M., Anderman, L. H., \& Jensen, J. M. (2010). Sense of belonging in college freshman at the classroom and campus levels. Journal of Experimental Education, 75(3), 203-220. https://doi.org/10.3200/JEXE .75.3.203-220
Frenzel, A. C., Becker-Kurz, B., Pekrun, R., Goetz, T., \& Lüdtke, O. (2018) Emotion transmission in the classroom revisited: $A$ reciprocal effects model of teacher and student enjoyment. Journal of Educational Psychology, 110(5), 628-639. https://doi.org/10.1037/edu0000228

Goldman, Z. W., \& Goodboy, A. K. (2014). Making students feel better: Examining the relationships between teacher confirmation and college students' emotional outcomes. Communication Education, 63(3), p259277. https://doi.org/10.1080/03634523.2014.920091

Hall, N., \& Webb, D. (2014). Instructors' support of student autonomy in an introductory physics course. Physical Review of Physics Education Research, 10(2), 020116. Retrieved July 16, 2020, from https://link.aps.org/ doi/10.1103/PhysRevSTPER.10.020116

Harrison, C. D., Nguyen, T. A., Seidel, S. B., Escobedo, A. M., Hartman, C., Lam, ... \& Tanner, K. D. (2019). Investigating instructor talk in novel contexts: Widespread use, unexpected categories, and an emergent sampling strategy. CBE-Life Sciences Education, 18(2), ar47. https://doi.org/ 10.1187/cbe.18-10-0215

Kim, C., \& Pekrun, R. (2014). Emotions and motivation in learning and performance. In Spector, J. M. (Ed.), Handbook of research on educational communications and technology (pp. 65-75). New York: Springer Science+Business Media.

Lin, Y., Durbin, J. M., \& Rancer, A. S. (2017). Perceived instructor argumentativeness, verbal aggressiveness, and classroom communication climate in relation to student state motivation and math anxiety. Communication Education, 66(3), 330-349. https://doi.org/10.1080/03634523.2016.1245427

Lizzio, A., Wilson, K., \& Simons, R. (2002). University students' perceptions of the learning environment and academic outcomes: Implications for theory and practice. Studies in Higher Education, 27(1), 27-52. doi: 10.1080/03075070120099359

Mainhard, T., Oudman, S., Hornstra, L., Bosker, R. J., \& Goetz, T. (2018, February). Student emotions in class: The relative importance of teachers and their interpersonal relations with students. Learning and Instruction, 53, 109-119. https://doi.org/10.1016/j.learninstruc.2017.07.011

Mazer, J. P. (2017). Students' discrete emotional responses in the classroom: Unraveling relationships with interest and engagement. Communication Research Reports, 34(4), 359-367. https://doi.org/10.1080/08824096 2017.1365233

Mazer, J. P., McKenna-Buchanan, T. P., Quinlan, M. M., \& Titsworth, S. (2014) The dark side of emotion in the classroom: Emotional processes as mediators of teacher communication behaviors and student negative emotions. Communication Education, 63(3), 149-168. https://doi.org/10.1080/ 03634523.2014 .904047

Merriam, S. B., \& Tisdell, E. J. (2016). Qualitative research: A guide to design and implementation (4th ed.). San Francisco, CA: Jossey-Bass.

Miller, C. M. I., \& Parlett, M. (1974). Up to the mark: A study of the examination game. London, England: Society for Research into Higher Education, Ltd.

Mimirinis, M. (2020). What do undergraduate students understand by excellent teaching? Higher Education Research \& Development doi: $10.1080 / 07294360.2020 .1847048$

Papanastasiou, E. C., \& Zembylas, M. (2008). Anxiety in undergraduate research methods courses: Its nature and implications. International Journal of Research and Method in Education, 31(2), 155-167. https:// doi.org/10.1080/17437270802124616

Pekrun, R. (1992). The impact of emotions on learning and achievement: Towards a theory of cognitive/motivational mediators. Applied Psychology: An International Review, 41(4), 359-376. https://doi.org/10.1111/ j.1464-0597.1992.tb00712.x

Pekrun, R. (2006). The control-value theory of achievement emotions: Assumptions, corollaries, and implications for educational research and practice. Educational Psychology Review, 18(4), 315-341. https://doi. org/10.1007/s10648-006-9029-9

Pekrun, R., Frenzel, A. C., Goetz, T., \& Perry, R. P. (2007). The control-value theory of achievement emotions: An integrative approach to emotions in education. In Schutz, P., \& Pekrun, R. (Eds.), Emotion in education (pp. 13-36). Amsterdam: Academic Press.

Pekrun, R., Goetz, T., Titz, W., \& Perry, R. P. (2002). Academic emotions in students' self-regulated learning and achievement: A program of qualitative and quantitative research. Educational Psychology, 37(2), 91105. https://doi.org/10.1207/S15326985EP3702_4 


\section{E. E. Schussler et al.}

Pekrun, R. P., \& Stephens, E. J. (2010). Achievement emotions in higher education. In Smart, J. C. (Ed.), Higher education: Handbook of theory and research (pp. 257-306). New York: Springer.

President's Council of Advisors on Science and Technology. (2012). Engage to excel: Producing one million additional college graduates with degrees in science, technology, engineering, and mathematics. Washington, DC: U.S. Government Office of Science and Technology. Retrieved June 17, 2016, from www.whitehouse.gov/administration/eop/ostp/ pcast/docsreports

Preston, C. C., \& Colman, A. M. (2000). Optimal number of response categories in rating scales: Reliability, validity, discriminating power, and respondent preferences. Acta Psychologica, 104(1), 1-15. doi: 10.1016/S0001 $-6918(99) 00050-5$

Reeve, J. (2009). Why teachers adopt a controlling motivating style toward students and how they can become more autonomy supportive. Educational Psychologist, 44(3), 159-175. doi: 10.1080/00461520903028990

Reeve, J., \& Shin, S. H. (2020). How teachers can support students' agentic engagement. Theory into Practice, 59(2), 150-161, doi: 10.1080/ 00405841.2019 .1702451

Respondek, L., Seufert, T., Stupinsky, R., \& Nett, U. E. (2017). Perceived academic control and academic emotions predict undergraduate university student success: Examining effects on dropout intention and achievement. Frontiers in Psychology, 8, ar243. https://doi.org/10.3389/ fpsyg.2017.00243

Seidel, S. B., Reggi, A. L., Schinske, J. N., Burrus, L. W., \& Tanner, K. D. (2015). Beyond the biology: A systematic investigation of noncontent instructor talk in an introductory biology course. CBE-Life Sciences Education, 14(4), ar43. https://doi.org/10.1187/cbe.15-03-0049
Seidel, S. B., \& Tanner, K. D. (2013). "What if students revolt?"-Considering student resistance: Origins, options, and opportunities for investigation. CBE-Life Sciences Education, 12(4), 586-595. https://doi.org/10.1187/ cbe-13-09-0190

Theobald, E. J., Hill, M. J., Tran, E., Agrawal, S., Arroyo, E. N., Behling, S., ... \& Freeman, S. (2020). Active learning narrows achievement gaps for underrepresented students in undergraduate science, technology, engineering, and math. Proceedings of the National Academy of Sciences USA, 117(12), 6476-6483. https://doi.org/10.1073/pnas.1916903117

Titsworth, S., McKenna, T. P., Mazer, J. P., \& Quinlan, M. M. (2013). The bright side of communication in the classroom: Do teachers' behaviors predict students' enjoyment, hope, and pride? Communication Education, 62(2), 191-209. doi: 10.1080/03634523.2013.763997

Witt, P. L., Schrodt, P., Wheeless, V. E., \& Bryand, M. C. (2014). Students' intent to persist in college: Moderating the negative effects of receiver apprehension with instructor credibility and nonverbal immediacy. Communication Studies, 65(3), 330-352. https://doi.org/10.1080/10510974.2013.811428

Young-Jones, A., Cara, K. C., \& Levesque-Bristol, C. (2014). Verbal and behavioral cues: Creating an autonomy-supportive classroom. Teaching in Higher Education, 19(5), 497-509. doi: 10.1080/13562517.2014 .880684

Young-Jones, A., Levesque, C., Fursa, S., \& McCain, J. (2019). Autonomy-supportive language in the syllabus: Supporting students from the first day. Teaching in Higher Education (preprint), 1-16. doi: 10.1080/13562517.2019.1661375

Zeidner, M., \& Matthews, G. (2005). Evaluation anxiety: Current theory and research. In Elliot, A. J., \& Dweck, C. S. (Eds.), Handbook of competence and motivation (pp. 141-166). New York: Guilford. 